\title{
VESICOURETERIC REFLUX AND VIDEOURODYNAMIC STUDIES: RESULTS OF A PROSPECTIVE STUDY AFTER THREE YEARS OF FOLLOW-UP
}

\author{
ROELOF J. SCHOLTMEIJER, M.D. \\ RIEN J. M. NIJMAN, M.D.
}

From the Department of Pediatric Urology, Erasmus University, Sophia Children's Hospital, Rotterdam, The Netherlands

\begin{abstract}
Objective. To study prospectively the influence of videourodynamic studies on the management of children with vesicoureteric reflux.

Methods. One hundred one children with reflux were investigated routinely with videourodynamic studies, as well as renal scans, ultrasound studies, and/or intravenous urograms. The studies were repeated at one, three, and five years. If bladder instability was demonstrated, the primary treatment consisted of anticholinergic drugs and antibiotics, regardless of the grade of reflux. In reflux Grades IV and V with instability and renal scars, surgery was performed. In case of a stable bladder, reflux Crades I-III received antibacterial treatment, while surgical correction was used for reflux Grades IV and V.

Results. The results of three years of follow-up of 101 children are reported. Bladder instability was found in 39 children. Thirty of them with reflux Grades I-IV and instability could be managed with anticholinergic and antibacterial drugs, while 9 needed surgical correction.

Conclusions. A voiding cystourethrogram is only sufficient for the detection of reflux but for correct management of these children a (video)urodynamic study is mandatory. After treatment of frequently found bladder dysfunction, the reflux will disappear in the majority of cases.
\end{abstract}

In the last fifteen years the management of vesicoureteric reflux has become more controversial and it is difficult to decide on the best form of treatment.

Several prospective studies were started with the aim to assess which patients should be considered for surgery and for which patients conservative management might be effective. ${ }^{1-3}$ Also attention has been directed toward vesicoureteric reflux in children with no overt abnormality other than urodynamically demonstrable dysfunction of the lower tract. $^{4-7}$

If reflux is viewed as a urodynamic abnormality, the cystographic diagnosis of reflux, even in combination with fluoroscopy, is not suitable for determining treatment. For this reason we started a

Submitted: September 29, 1993, accepted (with revisions): December 10, 1993 prospective videourodynamic study with the purpose of assessing more precisely which patients with vesicoureteric reflux have bladder dysfunction, whether they can be managed conservatively with anticholinergic drugs and antibacterial prophylaxis, and for which patients surgery is indicated.

In this article the results are reported after a follow-up period of three years.

\section{MATERIAL AND METHODS}

Children suspected of having vesicoureteric reflux underwent videourodynamic examinations between 1986 and 1990. The majority of the patients had recurrent urinary tract infections and received antibacterial treatment during a period of at least four weeks preceding the first videourodynamic study. Filling and voiding cystometry were performed and the urinary tract was visualized 
TABLE I. Results of conservative treatment of vesicoureteric reflux in 30 children with detrusor instability

\begin{tabular}{|c|c|c|c|c|c|c|}
\hline \multirow[b]{2}{*}{ Number of Ureters } & \multicolumn{6}{|c|}{ Reflux Grade After 3 Years } \\
\hline & $\overline{0}$ & 1 & II & III & IV & V \\
\hline Grade 0 & & 1 & 1 & & $1 *$ & \\
\hline Grade I: & 1 & & & & & \\
\hline Grade II: 14 & 5 & 3 & 6 & & & \\
\hline Grade III 13 & 7 & 4 & 1 & 1 & & \\
\hline Grade IV: 10 & 2 & 1 & 3 & 3 & 1 & \\
\hline Grade V: 1 & & & & & & $1^{*}$ \\
\hline *A successful reimplanta & 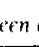 & & & & & \\
\hline
\end{tabular}

intermittently with each $50 \mathrm{~mL}$ increase of bladder volume, during an unstable contraction of the detrusor and during micturition, which was recorded on videotape. Reflux was graded according to the system of the International Reflux Study Committee ${ }^{\prime}$ and detrusor instability was diagnosed in cases of spontaneous detrusor contractions during the filling phase of the examination with an increase of detrusor pressure of at least 15 $\mathrm{cm}$ water, as recommended by the International Continence Society. ${ }^{8}$

All patients were also evaluated with an intravenous urogram (IVU) and a renal scan. Blood pressure was noted and laboratory tests including measurement of serum creatinine, urine analysis, and dip slide were performed. These examinations were repeated at one and three years and will be repeated at five years if reflux was still present at the three-year follow-up examination.

Classification of the findings on the intravenous urogram was done according to the recommendation of the International Reflux Study Committee.' Scarring was classified into four groups; A: not more than two parenchymal scars; B: more than two scars plus areas of significant parenchymal thinness; C: diffuse thinness of parenchyma with generalized calicectasis; D: shrunken kidney, no remaining parenchyma. Classification of the function of the refluxing kidney on the renal scan was based on the percentage of the total function delivered by this kidney.

The mode of treatment was based on the results of another prospective study. ${ }^{3}$ Children with reflux Grades I, II, and III were initially treated with a strict micturition regimen plus antibacterial treatment and prophylaxis. Surgical treatment was adopted for refluxes Grades IV and V, provided detrusor instability had been excluded. However, if there was detrusor instability, anticholinergic drugs and antibacterial treatment were given regardless of the grade of reflux, and the videourodynamic ex- amination was repeated after three to six months of therapy; but surgery was performed in reflux Grades IV and V with renal scars. In cases in which reflux Grades IV and V persisted, in recurrent urinary tract infections or at least two breakthrough infections in lower grades of reflux, or increase of reflux to at least Grade IV during follow-up, a reimplantation was performed. In patients who had no surgical treatment a videourodynamic examination was repeated at one and three years and will eventually be performed at five years. One hundred eighteen children entered the study. They had one hundred seventy-five refluxing ureters: sixtyone unilateral and fifty-seven bilateral. The mean age at presentation of 79 girls $(67 \%)$ and 39 boys $(33 \%)$ was five years (range, 6 weeks to 15 years). In 41 patients with detrusor instability (34.7\%) unilateral reflux was found in 24 and bilateral reflux occurred in 17 patients. In patients with a stable bladder there was no significant difference ( 37 unilateral and 40 bilateral).

For detrusor instability, the initial treatment in 37 children with fifty-two refluxing ureters of all grades of reflux consisted of anticholinergic drugs plus antibiotics, while surgery was performed because of renal scars in 4 children with six refluxing ureters Grade IV or V. Because of severe persistent reflux Grade IV or V, a reimplantation was done after six to twelve months in another 5 children with nine refluxing ureters.

In cases of a stable bladder the initial treatment consisted of antibiotics only in 49 children with sixty-eight refluxing ureters, while surgery was performed in 28 children with forty-nine refluxing ureters. Because of recurrent urinary tract infections or increase of reflux, a reimplantation was done after six to twelve months in 4 children with six refluxing ureters.

\section{RESULTS}

Of 101 children, 39 with detrusor instability and 62 with a stable bladder, data are available at threeyear follow-up.

\section{URODYNAMIC FINDINGS}

The results of conservative treatment (anticholinergic drugs plus antibiotics) in 30 children with detrusor instability are shown in Table l. In 3 children with unilateral reflux, the contralateral ureter showed reflux after three years. Recently 1 of them has been operated on with good success, because of reflux Grade IV. In fifteen of the thirtynine refluxing ureters the reflux has disappeared, while in another fifteen ureters the reflux has 
TABLE II. Results of conservative treatment of vesicoureteric reflux in 42 children with a stable detrusor

\begin{tabular}{|c|c|c|c|c|c|}
\hline \multirow[b]{2}{*}{ Number of Ureters } & \multicolumn{5}{|c|}{ Reflux Grade After 3 Vears } \\
\hline & 0 & 1 & II & III & IV \\
\hline Grade 0: 6 & & 1 & 3 & 2 & \\
\hline Grade 1.9 & 6 & 1 & 1 & & $1^{*}$ \\
\hline Grade II: 26 & 13 & 3 & 8 & 1 & $1 \dagger$ \\
\hline Grade III: 19 & 7 & & 6 & 4 & $2 \ddagger$ \\
\hline Grade IV: 3 & 1 & & & 1 & 1 \\
\hline \multicolumn{6}{|c|}{$\begin{array}{l}{ }^{\star} \text { Reflux only during micturition. } \\
\text { † Recently treated with a subostial injection of Teflon. } \\
\text { †Recently successfully reimplanted. }\end{array}$} \\
\hline
\end{tabular}

diminished to a lesser degree. Nine children with detrusor instability and fifteen refluxing ureters ( 1 Grade I, 3 Grade II, 8 Grade IV, and 3 Grade V) were all successfully treated with reimplantation. Persistent detrusor instability was found in 7 children only: 6 children after conservative treatment and 1 child after reimplantation.

The results of conservative treatment in 42 children with a stable detrusor are shown in Table II. In 6 children with initially unilateral reflux, reflux was found in the contralateral ureter after three years. Reflux disappeared in twenty-seven of the sixty-two refluxing ureters while in ten other ureters reflux was diminished to a lesser degree. One patient with reflux Grade I initially showed reflux Grade IV, but only during micturition. In 1 patient with reflux Grade II the reflux progressed to Grade IV. This ureter has been treated recently with a subostial injection of Teflon. In 2 other patients with reflux Grade III, the reflux deteriorated to Grade IV and a reimplantation was performed with good success.

In 20 children with thirty-two refluxing ureters and a stable detrusor, which were treated by surgery, reimplantation was successful in twentyeight ureters. In 1 patient with reflux Grade V in a poorly functioning kidney nephroureterectomy was performed as initial treatment, and in another child with reflux Grade IV in the left ureter, draining a poorly functioning kidney, and Grade II on the right side, nephroureterectomy was done on the left side after which the reflux in the right ureter disappeared. In 1 child with reflux Grade III on the right side and Grade V on the left side, no improvement was seen. Therefore a reimplantation was performed again, after which reflux Grade II persisted on the right side and Grade III on the left. Surgery was thus successful in 27 of 29 children (20 with a stable and 9 with an unstable bladder).
TABLE III. Renal scars in 101 children identified with intravenous urography

\begin{tabular}{|c|c|c|c|c|c|}
\hline \multirow{2}{*}{$\begin{array}{l}\text { Initial } \\
\text { Grade }\end{array}$} & \multicolumn{2}{|c|}{ Mode of Treatment } & & \multicolumn{2}{|c|}{$\begin{array}{c}\text { Number of Scars } \\
\text { at } 3 \text { Years }\end{array}$} \\
\hline & Surgery & Conservative & & Surgica & ervative \\
\hline \multirow[t]{2}{*}{ No scars } & 5 & & $A$ & 1 & \\
\hline & & & $C$ & 4 & \\
\hline$A$ & 6 & 7 & $A$ & 6 & 7 \\
\hline B & 4 & 3 & B & 4 & 3 \\
\hline C & $2^{*}$ & 3 & C & 1 & 3 \\
\hline$D$ & $4 \dagger$ & & $D$ & 2 & \\
\hline
\end{tabular}

${ }^{*}$ Renal duplication with severe scarring in the lower pole, treated by heminephrec tomy and reimplantation.

tNephroureterectomy for two kidneys.

\section{INTRAVENOUS UROGRAM FINDINGS}

On the initial urogram renal scars were found in twenty-nine of one hundred seventy-five kidneys (16.5\%) and after three years no increase in scars was seen in these kidneys (Table III). However in five kidneys with dilated calices and apparently normal parenchyma, renal scars were seen clearly at three-year follow-up. All these refluxing units with scars were initially treated by reimplantation. In one duplicated kidney with severe scarring (C) in the lower pole, heminephrectomy was performed in combination with a Lich-Gregoir antireflux procedure of both ureters at that side. Two shrunken, poorly functioning kidneys were removed. After three years, parenchymal scars were found in thirty-one of one hundred seventy-two kidneys (18\%).

\section{Renal SCAN AND SERUM CREATININE}

On the initial renal scan loss of function was seen in fifty-eight kidneys (33\%). In fifteen kidneys, of which three were treated by reimplantation, there was an improvement of the renal function to normal but in thirteen other kidneys (two treated by reimplantation) a slight deterioration of the renal function was noted (Tables IV and V). In 2 patients with a nonfunctioning kidney and a kidney with a function of less than 15 percent of the total, nephroureterectomy was performed. In thirtyseven of the fifty-eight kidneys with initial loss of renal function, the function remained unchanged.

In 11 children ( 3 in the conservative group) serum creatinine was initially slightly elevated, related to the age, but at three years the values were normalized in 6 children ( 2 in the conservative group) and remained slightly elevated in the other 5 children. In 1 patient in the conservative group with initially a normal serum creatinine, a slight elevation was seen at three years. 
TABLE IV. Number of kidneys with loss or improvement of renal function on the scan in the conservative treated group

\begin{tabular}{cccc}
\hline $\begin{array}{c}\text { Initial Percentage of } \\
\text { Total Renal Function }\end{array}$ & Number & $\begin{array}{c}\text { Percentage After } \\
3 \text { Years }\end{array}$ & Number \\
\hline$>45$ & 11 & $30-45$ & 11 \\
$30-45$ & 33 & $>45$ & 11 \\
& & $30-45$ & 18 \\
$15-50$ & 2 & $15-30$ & 4 \\
& & $50-45$ & 1 \\
& & $15-30$ & 1 \\
\hline
\end{tabular}

TABLE V. Number of kidneys with loss or improvement of renal function on the scan in the surgical treated group

\begin{tabular}{lccc}
\hline $\begin{array}{c}\text { Initial Percentage of } \\
\text { Total Renal Function }\end{array}$ & Number & $\begin{array}{c}\text { Percentage After } \\
3 \text { Years }\end{array}$ & Number \\
\hline$>45$ & 2 & $30-45$ & 2 \\
$30-45$ & 15 & $>45$ & 2 \\
& & $30-45$ & 13 \\
$15-30$ & 5 & $30-45$ & 1 \\
& & $15-30$ & 4 \\
$<15$ & $2^{*}$ & $<15$ & 1 \\
No function & $1^{*}$ & & \\
Nephroureterectomy of one kidney with a function of < 15 percent and an afunc- \\
tional kidney.
\end{tabular}

\section{URINARY TRACT INFECTION AND HYPERTENSION}

In the conservatively managed group, the urinary tract infections were successfully treated in all but 1 patient, and in the surgically treated group there were no recurrent urinary tract infections. In most of the cases antibacterial prophylaxis had already ceased. Hypertension was not found at the initial examination or at three years.

\section{COMMENT}

In addition to abnormal implantation of the ureter into the bladder, urinary tract infections, lower urinary tract dysfunction, high bladder pressures, and ureteric peristaltic abnormalities are important in the development of reflux. . $^{4-7,9}$

The results of videourodynamic investigations confirm that vesicoureteric reflux may be caused by bladder/urethra dysfunction and that in cases of detrusor instability reflux can be cured or diminished to a lesser degree by anticholinergic drugs and antibacterial treatment in combination with a strict voiding regimen, even in patients with reflux Grade IV. Anticholinergic therapy reduces the need for surgical treatment, and oxybutinine $\mathrm{HCl}$ has been proven to be an effective anticholinergic drug. ${ }^{10}$
On the initial IVU renal scars were found in 16.5 percent of the kidneys and during follow-up new renal scars were seen in only five kidneys $(2.8 \%)$. Occurrence of hypertension was not seen in the short surveillance period of this study. There was only $l$ child with recurrent urinary tract infections in the conservatively treated group, but in the group treated by surgery no recurrent infections were seen. This is in accordance with our first prospective study, ${ }^{3}$ and does not support the observation of the Birmingham Reflux Study Group ${ }^{2}$ that surgery did not prevent breakthrough urinary tract infection.

This study supports the findings of our previous work ${ }^{3}$ with respect to the preferred conservative treatment in reflux Grades I, II, and III. but in cases of detrusor instability anticholinergic drugs should be added, eventually in combination with a strict micturition regimen (clockwise micturition).

For reflux Grades IV with a stable detrusor and all reflux Grades V, surgery should be the primary treatment.

Voiding cystourethrography is suitable for the detection of vesicoureteric reflux, but a (video)urodynamic study is useful for making decisions regarding treatment. When the urodynamic examination is combined with fluoroscopy and recorded on videotape, the child has to be catheterized only once.

J. M. Nijman. M.D. Department of Pediatric l rology Sophia Children's Hospital

Dr. Molewaterplein 60 3015 RJ Rotterdam, The Netherlands

\section{REFERENCES}

1. Anonymous: Medical versus surgical treatment of primary vesicoureteral reflux: a prospective international study in children. J Urol 125: 277-283, 1981

2. Anonymous: Prospective trial of operative versus nonoperative treatment of severe vesicoureteric reflux in children: five years observation. Birmingham Reflux Study Group. Br Med J 295: 237-241, 1987.

3. Scholtmeijer RJ: Treatment of vesicoureteric reflux. Results of a prospective study. Br J Urol 72:346-349, 1993.

4. Koff SA, and Murtagh DS: The uninhibited bladder in children: effect of treatment on recurrence of urinary infection and on vesico-ureteral reflux resolution J Urol 130: $1138-1141,1983$.

5. Nielsen JB, Djurhuus JC, and Jorgensen IM: Lower urinary tract dysfunction in vesicoureteral reflux. Urol Int 39: $29-31,1984$.

6. Jorgensen TM: The pathogenic factors in vesicoureteral reflux. Neurourol Urodyn 5: 153-183, 1986.

7. Griffiths DJ, and Scholtmeijer RJ: Vesicoureteral reflux and lower urinary tract dysfunction: evidence for two different reflux/dysfunction complexes. I Urol 137: 240-244, 1987. 
8. Anonymous: Fourth report on the standardisation of terminology of lower urinary tract function. Terminology related to neuromuscular dysfunction of the lower urinary tract. Produced by the International Continence Society. $\mathrm{Br} \mathrm{J}$ Urol 53: 333-335, 1981

9. Scholtmeijer RJ, and Griffiths DJ: The role of videourodynamic studies in diagnosis and treatment of vesicoureteral reflux. J Pediatr Surg 25: 669-671, 1990.

10. Scholtmeijer RJ, and van Mastrigt R: The effect of oxyphenonium bromide and oxybutinin hydrochloride on detrusor contractility and reflux in children with vesicoureteral reflux and detrusor instability. J Urol 146: 660-662, 1991

\section{EDITORIAL COMMENT}

The importance of identifying detrusor instability in patients with reflux was established by Koff and Murtagh ${ }^{1}$ and Homsy et al. ${ }^{2}$ They found that patients with detrusor instability and reflux, when treated with oxybutinin and antibiotics, had a greater incidence of resolution compared with patients with reflux without detrusor instability who were treated with antibiotics alone. Whether oxybutinin is responsible for the resolution of the reflux is debatable. ${ }^{3}$ It is quite possible that reflux with detrusor instability is, primarily, a neurophysiologic "immaturity" of some children that is likely to resolve with time. A randomized, placebo-controlled trial ideally would be required to determine whether oxybutinin or other anticholinergics are any better than time alone in bringing about a resolution of the reflux.

What makes this study somewhat unique is the use of urodynamics to investigate all children with reflux, since neurogenic disease is recognized as the most common cause of reimplantation complications. ${ }^{4}$ The difficulty in interpreting urodynamics in a neurologically normal and often uncoop- erative child has limited its wide application. Children with reflux should be categorized as to detrusor and sphincter abnormalities. It is difficult to justify the cost and inconvenience of subjecting all patients to urodynamic studies. Urodynamics should at least be performed on patients with suggestive histories and physical signs.

The value of videourodynamics, as seen in this study, is that a single catheterization is required and that the study is usually performed by a urologist and/or radiologist. The question of radiation exposure requires further evaluation. In this series, there is no subclassification as to the type of urodynamic abnormalities such as lazy bladders, Hinman's syndrome, etc.

The study contributes to our understanding of reflux and in particular, should diminish the incidence of failed reimplantation and other complications of antireflux surgery.

\section{REFERENCES}

1. Koff SA, and Murtagh DS: The uninhibited bladder in children: effect of treatment on recurrence of the urinary infection and vesicle ureter reflux resolution. J Urol 130: 1138-1141, 1983.

2. Homsy YL, Nsouli I, Hamburger B, Laberge I, and Schick E: The effects of oxybutinin on vesicoureteral reflux in children. J Urol 134: 1168-1171, 1985.

3. Seruca $\mathrm{H}$ : Vesicoureteral reflux and voiding dysfunction: a prospective study. J Urol 142: 494-498, 1989.

4. Bauer SB, and Decter RM: The failed ureter reimplantation. Dialog Pediatr Urol 14: (1), 1991.

Hjalmar W Johnson, M.D. Department of Surgery University of British Columbia Vancouver, British Columbia, Canada 